\title{
EVALUATION FACTORS IN SEMANTIC MECHANISMS OF MANIPULATION (IN ITALIAN)
}

\author{
Olga A. Pogoretskaya \\ Moscow State Institute of International Relations (University), \\ 76, Prospect Vernadskogo, Moscow, 119454, Russia
}

\begin{abstract}
The aim of the article is to analyze the manipulative potential of the modern Italian-speaking media space in terms of creating a negative image of Russia as an international player. The sources of language material for the analysis are two authoritative Italian publications - Internazionale newspaper and Formiche.net Internet portal - characterized by the exclusively analytical content of articles and expert comments in the field of international relations and geopolitics, the authors of which are able to significantly influence the readership. The methodological apparatus includes a descriptive method and a method of semantic and syntactic analysis of linguistic units with a manipulative potential. From a pragmatic point of view, examples of evaluation predicates used by the Italian mass media to inform the reader about the actions of the Russian Federation are given. The article may be of interest to linguistic researchers dealing with romance studies, political linguistics, as well as to political scientists interested in Russian-Italian relations.
\end{abstract}

Key Words: linguistic manipulation, agenda-setting theory, image of Russia, Italian media space

For citation: Pogoretskaya O.A. 2020. Evaluation Factors in Semantic Mechanisms of Manipulation (in Italian). Philological Sciences at MGIMO. Vol. 6. No 4(24). P. 56-64. https://doi.org/10.24833/24102423-2020-4-24-56-64

\section{ФАКТОР ОЦЕНКИ В СЕМАНТИЧЕСКИХ МЕХАНИЗМАХ МАНИПУЛЯЦИИ (НА МАТЕРИАЛЕ ИТАЛЬЯНСКОГО ЯЗЫКА)}

\author{
О.А. Погорецкая
}

Московский государственный институт международных отношений (университет) МИД России, 119454, Москва, пр. Вернадского, 76

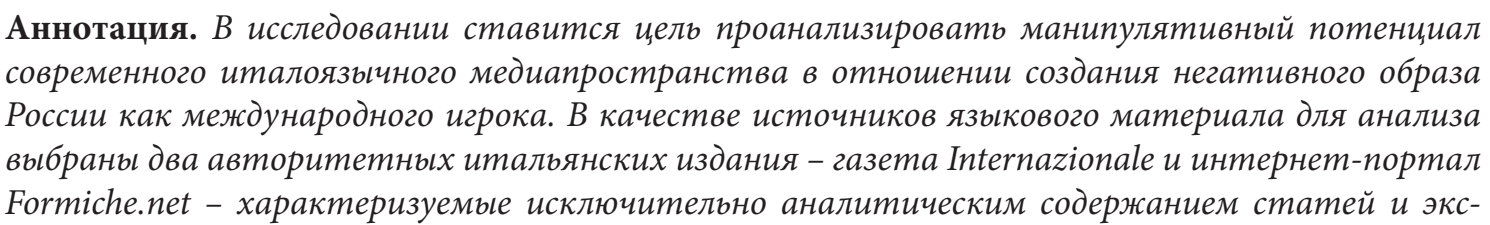


пертных комментариев в области международных отношений и геополитики, авторы которых способны в значительной мере повлиять на читательскую аудиторию. Методологический аппарат включает в себя описательныцй метод и метод семантического и синтаксического анализа языковых единии, обладающих манипулятивным потенциалом. С позиций прагматики приводятся примеры оценочных номинаций, используемых итальянскими СМИ при информировании читателя о действиях Российской Федерации. Статья может представлять интерес для лингвистов-исследователей, занимающихся проблемами романистики, политической лингвистики, а также политологов, интересующихся российско-итальянскими отношениями.

Ключевые слова: речевая манипуляция, теория установления повестки дня, оценка, скрытая оценочность, образ России, италоязычное медиапространство

Для цитирования: Погорецкая О.А. 2020. Фактор оценки в семантических механизмах манипуляции (на материале итальянского языка). Филологические науки в МГИМО. Том 6. № 4(24). С. 56-64. https://doi.org/10.24833/2410-2423-2020-4-24-56-64

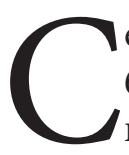

егодня невозможно представить повседневную жизнь социально активного человека без большого объёма знаний об окружающем мире и без медиапространства, которое открывает доступ к этому знанию. Потребность человека в информации разного рода является следствием растущей зависимости от общества и стремления осмыслить происходящее, приспособиться к нему.

Особенно актуально необходимость следить за политическими событиями звучит в Итальянской Республике, где общество сильно политизировано, и очень трудно найти человека, не соприкасающегося с миром политики в определённой степени.

Однако зачастую участие итальянцев в политической жизни страны сводится к тому, что их внимание фокусируется на политической жизни своего региона, в то время как интерес к политическим изменениям на уровне государства снижается. Это объясняется отчасти феноменом итальянской реалии под названием 'campanilismo' (местечковость, «патриотизм своей колокольни», привязанность к месту рождения, общественно-политический кругозор, ограниченный проблемами своего региона), отчасти необходимостью прилагать большие усилия для неповерхностного понимания политической обстановки в стране.

Стоит учитывать особую политическую обстановку, сложившуюся в Итальянской республике за последние десятилетия. Происходит быстрая смена правительств, перераспределение влияния политических партий, формирование новых коалиций, что бесспорно ведёт к острой политической и социальной полемике, представляющей крайне интересный материал для изучения манипулятивных стратегий в речи политических деятелей.

Среди экстралингвистических факторов, воздействующих на поведение электората, представляется возможным выделить, прежде всего, невысокий уровень знаний избирателей о политической культуре и ограниченное количество источников достоверной информации. С одной стороны, существует открытый доступ к огромному количеству информационных баз: ANSA (ocновное информационно-печатное агентство Италии), Mediaset (крупнейшая итальянская частная медиа- и телекоммуникационная компания), Rai (крупнейшая итальянская общественная телерадиокомпания), Asianews (агентство ПИМЕ - Папский институт иностранных миссий); с другой стороны, большинство этих источников субъективны, а выбор избирателя всё чаще сводится к поверхностному чтению заголовков газетных статей или постов в социальных сетях. Последние становятся зачастую основным источником информации не только из-за технически удобного доступа, но из-за того, что сами политики и журналисты всё чаще переносят свою деятельность в медиапространство. К примеру, Маттео Сальвини, один из ярких представителей итальянской политической сцены, стал активнее пользоваться социальными сетями в период взлёта своей карьеры и во многом пытается заручиться доверием избирателей, создавая в Инстаграме образ “своего”, публикуя свои фотографии из повседневной жизни и сопровождая их прямыми обраще- 
ниями к итальянцам (эмпатийное апеллирование к пользователям соцсетей - “vi abbraccio” (обнимаю вас), "con tutto il mio affetto" (со всей любовью), оценочные обращения - "cari amici" (дорогие друзья), а также постами о своих политических действиях, что представляется сильной формой воздействия на избирателя с помощью визуальных и вербальных средств [11].

Разумеется, взаимодействие в медиапространстве не сместилось полностью в пространство социальных сетей, официальные источники министерств и ведомств, правительственных организаций, авторитетных печатных и электронных изданий продолжают играть важную роль в формировании у избирателя того или иного понимания политической обстановки.

Важно отметить не только качество содержания представленного материала, но и форму и количество его подачи, то, что журналисты Маккомбс и Шоу из Университета Северной Каролины назвали «определением повестки дня» (“agenda setting”) [7]. Они являются авторами термина, хотя само понятие сформулировал и описал У. Липпман ещё в начале двадцатого века. В работе «Общественное мнение» автор называет средства массовой информации «связующей нитью», которая объединяет происходящие в мире события и людей, однако делает это опосредуя сами события, создавая альтернативные возможности их восприятия читателями [6] .

Американский исследователь, историк науки Бернард Коэн очень точно определил суть теории, он утверждал, что “прессе преимущественно не удаётся сказать людям, что думать, но она с большим успехом говорит им, о чём думать” [5, с. 13]. Дальнейшее развитие теории определения повестки дня (agenda-setting theory) привело к расширению терминологии и выявлению феномена общественного определения повестки дня (public agenda setting). Андреина Манделли подчёркивает важность исследования механизмов этого явления, так как новостные СМИ способны установить не только общественную повестку политических ситуаций, но и оказать влияние на повестку общественных ценностей, на мнение избирателей [7], что может привести к кардинальному изменению расстановки политических сил.

Французскому дипломату Ш.-М.Талейрану, который занимал пост министра иностранных дел Франции при трёх режимах в период с конца XVIII века до начала XIX века, известному своим мастерством политической интриги, приписывается афоризм, который как нельзя лучше характеризует оценочный характер речи: "Речь дана человеку для того, чтобы скрывать свои мысли". Каждое событие, имеющее определённое денотативное значение, может быть описано разными способами, с помощью слов с разной коннотацией. Именно через различную номинацию выражаются и внушаются противоположные оценки [3].

Особенно “результативными” в формировании “выгодного”, эмоционально окрашенного представления о той или иной стране в глазах аудитории оказываются различные речевые манипулятивные приёмы, к которым прибегают итальянские политики и журналисты при информировании населения о внешнеполитической обстановке и её оценке.

В рамках политического дискурса манипулятивные стратегии используются, чтобы повлиять не только на восприятие информации целевой аудиторией, но и на поведение электората; как указывает Е.И. Шейгал, одной из основных функций интенциональной базы политического дискурса является «создание «языковой реальности» поля политики и её интерпретация» $[4$, с. 9], а также «манипуляция сознанием и контроль за действиями политиков и электората» [там же].

Манипуляция как способ управления деятельностью сознания это прежде всего дискурсивное явление. Манипуляция направлена на скрытое управление мыслительными процессами человека: адресат получает «закодированное» определённым образом сообщение, которое на смысловом уровне расшифровывается необходимым для "манипулятора" способом. Медиапространство создаёт условия для возникновения у адресата требуемых ассоциативных связей, которые оказывают обусловливающее влияние (положительное или отрицательное, стимулирующее или ингибирующее) на мыслительные процессы, определяя по смыслу интерпретацию речевого знака в заданном контексте.

Любое знание вербализуется и кодируется в речевом знаке. Манипулятивный механизм реализуется на базе интерпретационного отношения между семантикой знака (слова, высказывания) и смысла, в котором важнейшую интерпретационную роль играет оценка. “Манипулятор”, 
предъявляя знак адресату, скрывает, переводит в план содержательной импликации оценку, которую он планирует “навязать” адресату. Манипулятивная оценка - не та, которая явно предъявляется адресату с тем, чтобы вызвать его ответную реакцию. Манипулятивная оценка как будто не требует ответной реакции адресата, её можно “не заметить”, “пропустить” как нечто несущественное. Однако, по принципу известного афоризма, “молчание адресата”, то есть отсутствие его реакции на имплицируемую оценку, автоматически воспринимается как “знак согласия”.

Логика манипулятивных оценочных импликаций может быть достаточно протяжённой, как в масштабе текста, так и в межтекстовом пространстве дискурса. Используя смысловую манипуляцию, манипулятор, тем не менее, действует не случайным образом, но преследует какую-то цель. Наступает момент, когда скрытая оценка (скрываемое адресантом отношение к описываемой реальности) переводится из импликации в план явного выражения, после чего адресат, уже “привыкший” и “смирившийся” с такого рода импликациями, вынужден соглашаться (полностью или частично) с подобной оценкой. Имплицируемая манипулятивная оценка становится общепризнанной и понимаемой как объективная характеристика объекта, становится общим правилом смыслового понимания данного объекта. Смысл начинает всё больше управлять семантикой знака.

“В информации, передаваемой средствами языка, всегда заключено определённое отношение языковой личности к единицам/формам/структурам языка, которые эта личность актуализирует с разной степенью осознанности и целенаправленности в своей речевой деятельности” [3, с. 8]. Итальянские СМИ не являются исключением. Особый интерес в качестве источника примеров дискурсивного манипулирования представляет газета Internazionale [9]. Это авторитетное периодическое издание, специализирующееся на внешней политике, было названо жюри старейшей и одной из важнейших в Италии премий в области журналистики il Premiolino “компетентным транслятором самого лучшего из зарубежных СМИ для итальянской публики” [10].

В своей работе по семантическому и композиционному анализу способов выражения оценки в италоязычном медиапространстве мы руководствуемся пониманием оценки, предикативной по своей природе, которое формулирует Н.Д. Арутюновой: «то, что (...) имеет отношение к действительным свойствам объектов, их соответствию или несоответствию норме (существующей и идеальной), восприятию объектов, вызываемым ими ощущениям (приятному и неприятному), к активному психологическому началу человека (его желаниям, стремлениям, воле, долгу, обязанностям), к решению и выбору из ряда альтернатив, к жизненной программе человека и идеалам человечества, к прескриптивной функции речи, реализующейся в определённых типах речевых актов (таких как одобрение, осуждение, поощрение, рекомендация, совет, инструкция, приказание, убеждение, разубеждение, призыв, запрет, рекламирование и др.)» [1, с. 59]. В развитие этого понятия в рамках исследования манипулятивных тактик и стратегий в масштабе текста и в масштабе дискурса можно ввести понятие “скрытой оценочности”. Скрытую оценочность может передавать любая номинация, которая не эксплицирует оценку, но реализует скрытую ассоциативно оценочную связь, то есть положительная или отрицательная оценка выводится из номинации логически. Скрытая оценочность - это не высказанная, а имплицируемая оценка.

С этих позиций нам прежде всего следует разделить оценочные номинации по критерию коммуникативной направленности на предмет скрытой и явной оценки.

Мы считаем, что по критерию коммуникативной направленности можно выделять регулятивную оценку, то есть то выражение, где оценка не вуалируется говорящим, а напротив, высказывается открыто, ярко, подчёркивая его позицию по тому или иному вопросу; говорящий как бы противопоставляет себя адресату (идёт “в атаку”, “испытывает” адресата на предмет согласия или несогласия со своей оценкой). Следствием такой оценки может послужить как начало полемики, дискуссии, борьбы мнений, так и, напротив, прекращение диалога ввиду неприятия оппонентом предложенного именования как неприемлемого или оскорбительного.

Примером такой оценочности может служить описание результатов референдума о присоединении Крыма к России в 2014 году в итальянской прессе как “annessione della Crimea alla Russia” (аннексия Крыма). Употребление слова “аннексия” вместо “присоединение” (adesione) 
встречается в большинстве италоязычных изданий и ярко отражает позицию редакции по данному вопросу: авторитетный словарь под редакцией Сабатини - Колетти (il Sabatini Coletti) определяет слово "annessione" как "Appropriazione politica e istituzionale di un territorio da parte di uno stato" / "политическое или институционное присвоение какой-либо территории другим государством" и даёт пример употребления "annessione dei territori conquistati” /аннексия завоёванHыx территорий/, в котором подчёркивается негативная оценочная коннотация, сопутствующая семантике этого слова.

Принципиально отличной от регулятивной оценки является оценка манипулятивная, целью которой является направить мысли адресата в нужное автору такого манипулятивно окрашенного высказывания русло, но сделать это скрытно, “исподтишка”, так, чтобы адресат не заметил, что им пытаются управлять. Примером такой манипулятивной оценки может служить оценочная номинация “Zar”, уже прочно закрепившаяся в италоязычном медиапространстве как синоним к президенту России В. Путину. “Lo zar Putin” - президент России выступает в роли «царя» этой крупнейшей и могущественной «державы», причём слово «царь» часто встречается с заглавной буквы, что, во-первых, привлекает ещё большее внимание, а во-вторых, подчёркивает статус денотата с графической точки зрения. С одной стороны, слово «царь» возвеличивает человека, может показаться лестным, подчёркивающим высокий статус говорящего, уважительное отношение к нему как к представителю легитимной власти; с другой стороны, эта же оценочная номинация может рассматриваться как инвектива, как намёк на чрезмерную “авторитарность”, “самодержавие”. Стоит также подчеркнуть функционирование оценочной номинации «царь» как дискурсивной метафоры, когнитивный потенциал которой позволяет реализовывать манипулятивные механизмы воздействия.

По результатам анализа статей, касающихся в той или иной степени России и опубликованных в период с 2018 по 2020 гг., можно сделать вывод о том, что применительно к Российской Федерации в италоязычном медиадискурсе встречается как регулятивная, так и манипулятивная оценка.

Россия представляется сильным и могущественным игроком на международной арене, о чём свидетельствует наличие большого количества оценочных номинаций, подчёркивающих влиятельность и авторитет Российской Федерации и уже ставших общеупотребительными, например, “potenza di primo piano". Определение России как «державы» ("роtenza”) усиливается определением «передовой, крупнейшей, на первом плане» (“di primo piano”). Параллельно, однако, создаётся образ России как агрессивного игрока, который злоупотребляет силой как внутри страны, так и во внешнеполитическом курсе.

По способу выразительного употребления выделяются непосредственный, дескриптивный, и косвенный, импликативный, модусы речевой оценки, используемые для характеристики и описания действий Российской Федерации:

- дескриптивные, то есть содержащие описательный элемент: lo scandalo sulle presunte infiltrazioni russe nella vita politica americana (скандал, связанный с предполагаемым вмешательством России в политическую жизнь американцев) - уточняя, что вмешательство России в выборы в США является «предполагаемым», автор снимает с себя ответственность за голословное обвинение России, однако намекает, что Россия способна на такое вмешательство; il leader russo e un leader dotato di grande fiuto politico (российский лидер обладает очень сильным политическим чутьём) - российский президент характеризуется как сильный, обладающий большой властью сразу за счёт трёх элементов, содержащих оценочную коннотацию - «dotato», «fiuto», "grande», причём манипулятивный потенциал последнего элемента усиливается за счёт препозиции прилагательного "grande" к существительному, благодаря чему это прилагательное приобретает значение «великий, выдающийся»; strategia ibrida di intimidazione militare e guerra mediatica (гибридная стратегия военного запугивания и медийной войны) - внутриполитическая линия российского правительства описывается при помощи обращения к речевым реализациям концепта «вражда», «борьба» (лексемы «strategia», «intimidazione», «militare», «guerra»); Putin è capace di muoversi da protagonista sulla scena internazionale (Путин способен выступать в роли главного героя на международной арене); 
- ммплкативные, то есть косвенно характеризующие способ выразительного предъявления оценки, которые подчёркивают в когнитивном плане позицию адресанта. На первый план выдвигается модус апелляции говорящего к адресату, выражаемый через оценочный предикат, способный передавать модальность: non c’è da sorprendersi che la quarantena non sia vista come unazione coordinata di cittadini responsabili (неудивительно, что карантин не был воспринят как необходимость согласованных действий со стороны ответственных граждан) - модальное выражение «non cè da sorprendersi che» подчёркивает отсутствие у автора сомнений в безответственности россиян; presto vedremo come l’epidemia e le sue conseguenze distruttive sulla sanità nazionale e sulleconomia saranno sfruttate (скоро мы увидим, как губительные последствия эпидемии будут эксплуатировать) - глагол в изъявительном наклонении, в сочетании с оценочным суждением «presto» указывает на уверенность в том, что губительных для населения и экономики страны последствий не избежать, но они будут использоваться в корыстных целях.

Коснёмся скрытых семантических механизмов явной оценки. Любая оценка выполняет интерпретативную функцию, несёт интерпретативную нагрузку и в этом своём статусе характеризуется относительностью, впрочем, относительность - это субъективно-различительный признак оценки (в плане её субъективного “авторства”, в чём говорящий противопоставляет свою оценку потенциальной оценке адресата; всякая оценка - это его авторская “находка”). Однако, с другой стороны, всякая оценка претендует на объективную истинность, подаёт себя как некий смысловой абсолют; в этом проявляется то, что можно назвать «истинностным авторитаризмом» оценки. Говорящий навязывает адресату свою оценку как некую абсолютную истину. Этой проблемы касается Н.В. Иванов: “Найдя истину, субъект тут же присваивает её себе, выдвигая себя вперёд как автора найденной истины. Напротив, сказав нечто эмоциональное, обнажающее его чувства или внезапное волнение, субъект прячется за объект, прикрывается внешней причиной, выставляя её как подлинное основание смысла" [2, с. 57].

Однако именно в «истинностным авторитаризме» оценки более всего обнаруживается её неистинность, то есть её интерпретационная либо чрезмерность, либо недостаточность (что мы видим, например, в различного рода эвфемизмах и дисфемизмах). Адекватность оценки реальному объекту или ситуации - вещь трудно доказуемая. Однако именно этим фактором, то есть смысловой дистанцией между семантикой предметного описания и оценкой более всего пользуются манипуляторы, которые с лёгкостью затушёвывают или, наоборот, раздувают негативное, преследуя свои цели.

Рассмотрим несколько примеров лексем, относящихся к описанию внутренней политики РФ: il discorso marziale di Putin / воинственная речь Путина - для описания обращения президента России использовано экспрессивное определение “marziale”, подчёркивающее “воинственную” позицию выступающего. Однако речь Путина не содержала никаких угроз. В его речи была лишь жёсткая оценка действий Запада. Именно это вызвало крайнее недовольство западных политиков. Данная оценка - характерный дисфемизм по отношению к России. In vista non c’e alcuna apertura liberale / не предвидится никаких либеральных взглядов - утверждение об отсутствии либерализма в России усиливается отрицательным местоимением 'alcuna', указывая на то, что либерализации взглядов в России, по мнению автора высказывания, не предвидится; tentativi maldestri di controllo sociale a Mosca / грубые попытки социального контроля в Москве - прилагательное 'maldestro' усиливает инвективу - звучит косвенное осуждение российского правительства за ведение жёсткой социальной политики.

Приведём примеры других дисфемизмов, используемых в итальянской прессе в отношении России.

Похожая оценочная линия, основанная на концептах «война», «борьба», «власть», выстраивается у большинства авторов (Pierre Haski; Gabriele Crescente; Andrea Gullotta, Gwynne Dyer, Annalisa Camilli) касательно действий и позиции России в различных регионах мира: развитие отношений России с Ираком называется - la Russia prova a prendersi l'Iraq / Россия пытается прибрать себе Ирак; развитие отношений с Венесуэлой - lo zampino russo nel settore energetico del Venezuela / вмешательство со стороны России в энергетику Венесуэлы - выбор автора высказы- 
вания в пользу возвратной формы глагола 'prendere' и разговорной лексемы 'zampino' снижает стилистический регистр высказывания и инсинуирует несоответствие общепринятым нормам дипломатического поведения.

Трудно представить себе “голую” оценку. Оценка не может появиться в речи, в тексте без того, чтобы что-то её обосновывало с фактической стороны. Предметно-семантическое обоснование, явно выраженное или имплицируемое, - необходимый спутник и “изнанка” всякой оценки. Если оценка не соответствует фактам, нечистоплотный журналист выдумывает эти факты. Ему требуется риторическое обоснование оценки. Характерен следующий пример: L’aviazione russa sta bombardando scuole e ospedali commettendo palesemente crimini di guerra - российская авиация бомбит школы и больницы, открыто совершая военные преступления (официально ни одного случая такого не было, но обвинения предъявляются). Далее следует: bisogna prendere le misure volte a scoraggiare l'aggressione russa / необходимо принять меры по сдерживанию российской агрессии. Журналист выдумывает факты, чтобы как можно ярче предъявить негативные оценочные суждения «сrimini di guerra» и «aggressione».

В условиях постоянного информационного шума и переизбытка информации следует отметить также особую роль семантического и синтаксического оформления заголовков как средства речевой манипуляции. К примеру, в статье "Russia, Cina e investimenti. In tre giorni, tutte le sfide per Nato e Difesa europea" [8] в заголовок вынесены “главные” проблемы для стран-членов НАТО в преддверии встречи министров обороны ЕС - “Россия, Китай, инвестиции”; перечисляется всего три проблемных для НАТО и европейской безопасности вектора: Россия - на первом месте, с точки зрения синтаксического построения заголовка, немедленно обращает на себя внимание читателя, поскольку стоит в препозиции. Россия определяется как одна из основных угроз безопасности Европы, что настраивает читателя на восприятие России как “проблемы”, решение которой избавит граждан ЕС от необходимости беспокоиться о собственной безопасности. Подобное перечисление может рассматриваться как попытка искажения объективной информации с помощью речевых манипулятивных приёмов, в этом случае на синтаксическом уровне. В этом заголовке устанавливается ассоциативная связь лексем «sfida» и «Россия». Ещё не прочитав статью, читатель сталкивается с довольно агрессивной оценкой на синтаксическом уровне, имеющей мощный манипулятивный потенциал. Эта оценка получает дальнейшее усиление. В одном из подзаголовков в указанной выше статье находим словосочетание “le minacce russe...” (российская угроза). Автору статьи представляется, что касательно внешней политики, основное внимание в постковидной реальности приковано к «угрозе» со стороны России - «...Al primo posto resta la sfida russa» (на первом месте остаётся вызов со стороны России). Приводится цитата генсекретаря НАТО Йенса Столтенберга (Jens Stoltenberg), который объяснил, что на повестке дня - угроза безопасности Европы со стороны постоянно растущего ядерного арсенала России. (In agenda ci sono le implicazioni sulla sicurezza "della crescita dell'arsenale nucleare missilistico" di Mosca, ha spiegato in conferenza stampa Jens Stoltenberg, segretario generale della Nato). Для создания у читателя уверенности в наличии "российского угрозы" приводится ещё одна цитата: "Россия продолжает наращивать ядерный потенциал”, что служит своего рода “оправданием” такого серьёзного обвинения в адрес Российской Федерации, ведь на самом деле Россия находится в рамках договора CHB. "La Russia ha continuato a modernizzare le proprie capacità missilistiche, comprese quelle ipersoniche" - поэтому в ходе встречи запланирована разработка «нового пакета мер политических и военных по повышению сдерживания России» («Per questo, si prevede da vertice un nuovo pacchetto di politiche e misure militari volte a innalzare la deterrenza»). «Deterrenza» - характерный давний западный эвфемизм, который свою агрессивную политику по отношению к России именует «сдерживанием».

При лексико-грамматическом и синтаксическом анализе популярных новостных итальянских СМИ Internazionale.it и Formiche.net было отмечено, что итальянский медиадискурс изобилует оценочными суждениями при освещении новостей из России. Особенно яркой представляется оценка для создания образа России-агрессора при описании внешнеполитического курса Российской Федерации, что становится возможным за счёт всё более утончённой конкурентной борьбы за потребителя информационных услуг в контексте современного медиапространства. 
Между оценкой и семантикой предметного описания нельзя постулировать абсолютную логическую выводимость оценочно смысловой характеристики из семантики предметного описания. Оценка нередко оказывается неадекватной объекту описания, что мы наблюдаем в различных манипулятивных стратегиях в прессе. Манипулятор навязывает такого рода оценку аудитории, оценка становится основанием фактических искажений, придумывания несуществующих фактов. Ложная манипулятивная оценка должна быть оправдана перед аудиторией, и это оправдание осуществляется в форме поиска и предъявления ложных фактов, событий. Ложные оценочные инвективы и инсинуации нередко характерны для западной и, в частности, итальянской прессы при описании событий, относящихся к России.

(C) Погорецкая O.A., 2020

\section{Список литературы}

1. Арутюнова Н.Д. Типы языковых значений. Оценка. Событие. Факт. М.: Наука, 1988. 344 с.

2. Иванов Н.В. О началах феноменологической парадигмы в языкознании. // Военно-гуманитарный альманах. Серия «Лингвистика». Вып. №5. T.1. «Язык. Коммуникация. Перевод». Материалы XIV Межд. науч. конф. по актуальным проблемам теории языка и коммуникации. Москва. ВУ (26 июня 2020 г.). М.: Изд. «Наука», 2020. С. 53-63.

3. Чернявская Е.В. Дискурс власти и власть дискурса: проблемы речевого воздействия. М.: Флинта, 2006. 136 с.

4. Шейгал Е.И. Семиотика политического дискурса. Волгоград: Гнозис, 2004. 328 с.

5. Cohen B. The Press and Foreign Policy. Princeton, 1963. 288 p. 5.

6. Lippmann W. Public Opinion. New York: Harcourt, Brace \& Co., 1922. 242p.

7. McCombs M., Shaw D.L., Weaver D. Communication and Democracy: Exploring the Intellectual Frontiers in Agenda-Setting Theory. Routledge, New York and London, 1997. Chapter 14 - Setting the Agenda for Cross-National Research: Bringing Values Into the Concept - Holli A. Semetko and Andreina Mandelli. 288 p.

8. Информационный портал Formiche.net (Италия) - 05.05.2018, 07.09.2019, 03.03.2020.

9. Издание Internazionale (Италия) - 20.07.2018, 17.12.2019, 05.02.2020.

10. Официальный сайт журналистской премии Il Premiolino (Италия) - 10.09.2020.

11. Официальный инстаграм-профиль Маттео Сальвини - 15.04.2020.

\section{References}

1. Arutiunova, N.D. Tipy iazykovykh znachenii. Otsenka. Sobytie. Fakt [Types of language values. Evaluation. Event. Fact] Moscow: Nauka, 1988. 344 c.

2. Ivanov, N.V. O nachalakh fenomenologicheskoi paradigmy v iazykoznanii [On the Beginning of a Phenomenological Paradigm in Linguistics] // Voenno-gumanitarny almanakh. Seriia Lingvistika. Vyp. 5 Tom 1. "Iazyk. Kommunikatsiia. Perevod." [Military Humanities Almanac. Series «Linguistics». Issue No. 5. T.1. «Language. Communication. Translation». Materials of the XIV International scientific conference on topical problems of the theory of language and communication]. Moscow. VU (June 26, 2020). Moscow: «Science» Publishing House, 2020. C. 53-63.

3. Chernyavskaya, E.V. Diskurs vlasti $i$ vlast diskursa: Problemy rechevogo vozdeystviia [Power Discourse and Discourse Power: Problems of Speech Impact]. Moscow: Flint, 2006. 136 c.

4. Sheygal, E.I. Semiotika politicheskogo diskursa [Semiotics of political discourse]. Volgograd: Gnosis, 2004. 328 c.

5. $\quad$ Cohen, B. The Press and Foreign Policy. Princeton, 1963. 288 p. 5.

6. Lippmann, W. Public Opinion. New York: Harcourt, Brace \& Co., 1922. 242 p.

7. McCombs, M. Communication and Democracy: Exploring the Intellectual Frontiers in Agenda-Setting Theory. (McCombs, M., Shaw, D.L., Weaver, D) Routledge, New York and London, Chapter 14 - Setting the Agenda for Cross-National Research: Bringing Values Into the Concept - Holli A. Semetko and Andreina Mandelli. 1997. 288 p.

8. Information portal Formiche.net (Italy) - 05.05.2018, 07.09.2019, 03.03.2020.

9. The edition of Internazionale (Italy) - 20.07.2018, 17.12.2019, 05.02.2020.

10. The official website of the Il Premiolino journalistic prize (Italy) - 10.09.2020.

11. Matteo Salvini's official installation profile -15.04 .2020 .

\section{Сведения об авторе:}

Погорецкая Ольга Андреевна - преподаватель кафедры романских языков им. Т.З. Черданцевой МГИМО (Россия, Москва). Сфера научных и профессиональных интересов: политическая лингвистика, речевое манипулирование, внешняя политика Италии.

E-mail: o.pogoretskaya@inno.mgimo.ru

Конфликт интересов: Автор заявляет об отсутствии конфликта интересов. 


\section{About the author:}

Olga Pogoretskaya - Professor of Department of Romance Languages, MGIMO University (Moscow, Russia). Spheres of research and professional interest: political linguistics, verbal manipulation, Italy's foreign policy. E-mail: o.pogoretskaya@inno.mgimo.ru

Conflicts of interest: The author declares absence of conflicts of interest. 